\title{
A High Efficiency Chlorophyll Sensitized Solar Cell with Quasi Solid PVA Based Electrolyte
}

\author{
H. C. Hassan, Z. H. Z. Abidin, F. I. Chowdhury, and A. K. Arof \\ Centre for Ionics University Malaya, Department of Physics, University of Malaya, 50603 Kuala Lumpur, Malaysia \\ Correspondence should be addressed to A. K. Arof; akarof@um.edu.my
}

Received 5 November 2015; Revised 5 January 2016; Accepted 13 January 2016

Academic Editor: Juan M. Coronado

Copyright (C) 2016 H. C. Hassan et al. This is an open access article distributed under the Creative Commons Attribution License, which permits unrestricted use, distribution, and reproduction in any medium, provided the original work is properly cited.

\begin{abstract}
The objective of this work is to investigate the performance of chlorophyll sensitized solar cells (CSSCs) with gel electrolyte based on polyvinyl alcohol (PVA) with single iodide salt (potassium iodide (KI)) and double salt (KI and tetrapropylammonium iodide (TPAI)). Chlorophyll was extracted from the bryophyte Hyophila involuta. The CSSC with electrolyte containing only KI salt produced a short circuit current density $\left(J_{\mathrm{sc}}\right)$ of $4.59 \mathrm{~mA} \mathrm{~cm}^{-2}$, open circuit voltage $\left(V_{\mathrm{oc}}\right)$ of $0.61 \mathrm{~V}$, fill factor $(\mathrm{FF})$ of 0.64 , and efficiency $(\eta)$ of $1.77 \%$. However, the CSSC with double salt electrolyte exhibited $J_{\text {sc }}$ of $5.96 \mathrm{~mA} \mathrm{~cm}^{-2}, V_{\text {oc }}$ of $0.58 \mathrm{~V}$, fill factor FF of 0.58 , and $\eta$ of $2.00 \%$. Since CSSC with double salt electrolyte showed better efficiency, other cells fabricated will use the double salt electrolyte. On addition of $0.7 \mathrm{M}$ tetrabutyl pyridine (TBP) to the double salt electrolyte, the cell's efficiency increased to $2.17 \%$, $J_{\text {sc }}=5.37 \mathrm{~mA} \mathrm{~cm}^{-2}, V_{\mathrm{oc}}=0.55 \mathrm{~V}$, and $\mathrm{FF}=0.73$. With $5 \mathrm{mM}$ chenodeoxycholic acid (CDCA) added to the chlorophyll, the light to electricity efficiency increased to $2.62 \%$ with $J_{\mathrm{sc}}$ of $8.44 \mathrm{~mA} \mathrm{~cm}^{-2}, V_{\mathrm{oc}}$ of $0.54 \mathrm{~V}$, and FF of 0.58 .
\end{abstract}

\section{Introduction}

One of the renewable energy sources that can fulfill the global energy demands is the dye sensitized solar cell (DSSC). It is simple, environmentally friendly, and relatively cheap to fabricate [1]. Among the many factors that affect the overall light to electricity conversion efficiency are the type of catalyst employed in the counter electrode, light transmission, substrate conductivity, dye sensitizer, the blocking substrate, and the band gap of the semiconductor used. DSSCs comprise a sealed assembly of dye-coated mesoporous semiconducting oxide nanoparticle photoanode covered with a redox couple containing gel electrolyte and a counter electrode [2]. Energy conversion in DSSCs begins when the photoexcited electrons of the dye are injected into the semiconducting layer and finally transported through the external circuit to the counter electrode. At the counter electrode, the electrons are returned to the hole in the dye molecule by the redox mediators. The dye is regenerated and produces electricity [3].

Commercial dyes in DSSCs are usually synthetic dyes, such as di-tetrabutylammonium cis-bis(isothiocyanato)bis(2,2' -bipyridyl-4,4' -dicarboxylato) ruthenium (II), commercially coded as N719, and cis-bis(isothiocyanato) bis (2,2' -bipyridyl- $4,4^{\prime}$-dicarboxylato) ruthenium (II), commercially coded as $\mathrm{N} 3$, both of which enhance the light to electricity conversion efficiency. Unfortunately, these dyes are expensive, environmentally unfriendly and contain ruthenium metal. In order to avoid using such dyes, natural dyes have been sought for as alternatives. Dyes and pigments derived from plants, for example, chlorophyll, anthocyanin, tannin, and carotene, are cheap and do not pose any environmental issues [4].

The use of liquid electrolytes in solar cells makes the device prone to leakage. Liquid electrolytes may contain volatile and corrosive components that can affect longevity of the solar panel. To overcome these problems, gel or quasi solid polymer electrolytes have been used by the researchers [5]. As an example, our group have successfully fabricated quasi solid state DSSCs using gel polymer electrolytes (GPEs) based on polyvinyl alcohol (PVA) [6]. PVA is nontoxic, biocompatible, biodegradable, easy to prepare, and chemically and thermally stable and has excellent mechanical strength [7].

Iodide salts and KI with iodine are used to produce the $\mathrm{I}^{-} / \mathrm{I}_{3}^{-}$redox couple which is employed for solar cell 
TABLE 1: Composition of the GPEs.

\begin{tabular}{lccccccccc}
\hline Sample & PVA $(\mathrm{g})$ & DMSO $(\mathrm{g})$ & $\mathrm{EC}(\mathrm{g})$ & PC $(\mathrm{g})$ & $\mathrm{KI}(\mathrm{g})$ & TPAI $(\mathrm{g})$ & $\mathrm{I}_{2}(\mathrm{~g})$ & TBP $(\mathrm{g})$ & TBP $(\mathrm{molar})$ \\
\hline PVA + single salt & 0.200 & 2.200 & 0.300 & 0.400 & 0.420 & 0.000 & 0.065 & - & - \\
PVA + double salt & 0.200 & 2.200 & 0.300 & 0.400 & 0.294 & 0.126 & 0.055 & - & - \\
PVA + double salt + 0.3 M of TBP & 0.200 & 2.200 & 0.300 & 0.400 & 0.294 & 0.126 & 0.055 & 0.091 & 0.3 \\
PVA + double salt + 0.5 M of TBP & 0.200 & 2.200 & 0.300 & 0.400 & 0.294 & 0.126 & 0.055 & 0.152 & 0.5 \\
PVA + double salt + 0.7 M of TBP & 0.200 & 2.200 & 0.300 & 0.400 & 0.294 & 0.126 & 0.055 & 0.213 & 0.7 \\
\hline
\end{tabular}

fabrication. Tetrabutyl pyridine (TBP) is an additive in the redox electrolyte that can influence the open circuit voltage [8], the electron injection yield, and the electron diffusion coefficient. It has been reported that TBP increases $V_{\text {oc }}$ significantly, while $J_{\mathrm{sc}}$ is not affected considerably or slightly decreased in DSSCs [9].

The natural dye, chlorophyll, can be extracted from a bryophyte species Hyophila involuta and used as the photosensitizer in DSSC. Hyophila involuta is a common and widespread species of the bryophyte moss [10]. This species is easy to obtain and it has high chlorophyll concentrations [11]. Hence, there is potential for its use in dye sensitized solar cells. The chlorophyll was extracted using ethanol. Chang et al. [12] reported $0.9 \%$ photoelectric conversion efficiency $(\eta)$ of DSSC using chlorophyll extracted from wormwood and electrolyte containing LiI and 4-tert-butylpyridine in acetonitrile (ACN). Various attempts have been undertaken to enhance the performance of DSSCs using natural sensitizers in view of their being environmental friendly and low cost. Incorporation of different additives or coadsorbents has become an effective effort for further improvement of the performance of DSSC. For instance, Kay and Gräetzel [13] observed that cholic acid (CA) with porphyrin derivatives can upgrade both photocurrent and photovoltage of DSSC. Moreover, there are other reports which address a number of coadsorbents such as hexadecylmalonic acid (HDMA) [14], 1-decyl phosphonic acid (DPA) [15], 3-phenylpropionic acid (PPA) [16], deoxycholic acid (DCA) [17], and chenodeoxycholic acid (CDCA) [18]. Among all the coadsorbents in DSSC devices, CDCA is the most effective agent as it has a huge hydrophobic tail and a hydrophilic head $(-\mathrm{COOH}$ group). It efficiently reduces dye aggregation and electron recombination via the formation of a thin passivation layer on the vacant $\mathrm{TiO}_{2}$ surface resulting in improvement of photonto-electron conversion efficiency [19-22]. Though CDCA has been used extensively in DSSC by different researchers, so far to our knowledge no or very few systematic works were done on the effect and functionality of CDCA in chlorophyll sensitized solar cell. The present work aims to fill this gap and to understand the role of coadsorbent CDCA in chlorophyll sensitized solar cell.

In this work, we fabricated DSSCs employing PVA based GPE doped with single salt (KI) and double salt (KI and TPAI) electrolytes. Chlorophyll extracted from a species of a Hyophila involuta was used as sensitizer. TBP and CDCA have been added in the various ways mentioned in the following sections in order to improve performance of the CSSCs.

\section{Experimental}

2.1. Materials. Poly(vinyl alcohol) or PVA ( $99 \%$ hydrolyzed), ethylene carbonate (EC), propylene carbonate (PC), tetrabutyl pyridine (TBP), and ferulic acid (99\%) were purchased from Sigma Aldrich. Potassium iodide (KI) was procured from Univar Analytical Reagent. Dimethyl sulfoxide (DMSO) was purchased from Friendemann Schmidt Chemical. Chenodeoxycholic acid (CDCA) was purchased from Solaronix.

2.2. Gel Polymer Electrolyte Preparation. The composition of the optimized PVA based gel polymer electrolytes (GPEs) was taken from Aziz et al. (2013) [23]. For the single salt electrolyte preparation, $2.2 \mathrm{~g}$ DMSO solvent was mixed with $0.42 \mathrm{~g}$ potassium iodide (KI), $0.3 \mathrm{~g}$ ethylene carbonate (EC), and $0.4 \mathrm{~g}$ propylene carbonate (PC). The mixture was stirred until a homogenous solution was obtained. An amount of $0.2 \mathrm{~g}$ PVA was then added into the homogenous solution. The mixture was stirred at $110^{\circ} \mathrm{C}$ until a homogeneous gel is formed. When the hot gel has cooled to ambient, iodine, $\mathrm{I}_{2}$, was added and stirred until iodine has completely diffused in the gel. Tetrapropylammonium iodide (TPAI) was added to the previous GPE system at specific ratios that have been tabulated in Table 1 to prepare the double salt PVA based GPE. Another comparative study was also conducted by adding TBP to the photoanode $\mathrm{TiO}_{2}$. The photoanode was soaked in TBP for $1 \mathrm{~h}$.

\subsection{Electrode Preparation}

2.3.1. Substrate Cleaning Process. The fluorine-doped tin oxide (FTO) conducting substrate was cleaned using a detergent. The substrate was then rinsed to remove excess detergent with distilled water. Finally it was washed with acetone and dried. The dried conducting substrate was then soaked in propanol until boiling to remove residual dirt. The dried FTO glass was then kept in a petri dish to be used later.

2.3.2. $\mathrm{TiO}_{2}$ Paste Preparation. The compact or blocking layer consisted of $0.5 \mathrm{TiO}_{2}$ (P-90) powder of size $15 \mathrm{~nm}$. It was ground in $2 \mathrm{~mL} \mathrm{HNO}_{3}(\mathrm{pH}=1)$ for $30 \mathrm{~min}$. This blocking layer will prevent the electrolyte from touching directly the conductive FTO glass that may cause shorting. The slurry obtained was spin-coated on the cleaned FTO substrate. The substrate was partly taped for electrical contacts. The coated glass was sintered at $450^{\circ} \mathrm{C}$ for $30 \mathrm{~min}$. A second but porous 


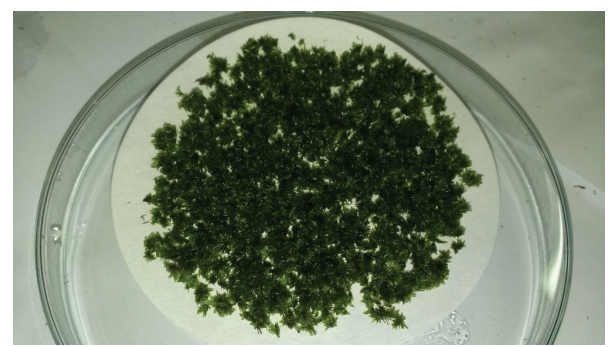

FIGURE 1: The moss species of Hyophila involuta.

layer of $\mathrm{TiO}_{2}$ (P-25) was then applied on the blocking layer. The size of P-25 $\mathrm{TiO}_{2}$ after drying is $21 \mathrm{~nm}$. For the porous layer, $0.5 \mathrm{~g} \mathrm{P}-25 \mathrm{TiO}_{2}$ powder was ground in $2 \mathrm{~mL} \mathrm{HNO}_{3}$ $(\mathrm{pH}=1)$ for $30 \mathrm{~min} . \mathrm{HNO}_{3}$ was added dropwise into the P-25 $\mathrm{TiO}_{2}$ powder. Poly(ethylene glycol) carbowax $(0.1 \mathrm{~g})$ was added to create porosity upon heating. A few drops of surfactant were added to the acidified $\mathrm{TiO}_{2}$ powder and ground using a mortar and pestle. The paste obtained was applied to blocking layer using the doctor blade method. The active area was $0.25 \mathrm{~cm}^{2}$. The assembly was heated at $450^{\circ} \mathrm{C}$ for another $30 \mathrm{~min}$. The carbowax will be evaporated and the second layer will become porous providing more surface area for the dye to adsorb on the surface of the porous $\mathrm{TiO}_{2}$.

2.3.3. Sensitizer Preparation. The chlorophyll was solventextracted from the Hyophila involuta moss (Figure 1). The Hyophila involuta moss was chosen as the chlorophyll source. The moss sample was cleaned three times to remove unwanted materials. A $5 \mathrm{~g}$ mass of the cleaned moss was soaked in $5 \mathrm{~g}$ alcohol overnight for the extraction of chlorophyll. The extract was kept at $4^{\circ} \mathrm{C}$.

2.4. Fabrication of Solar Cells. The coated FTO glass was soaked in the chlorophyll solution. To ensure chlorophyll adsorption, immersion was prolonged to 12 hours. A small amount of the prepared GPE was applied on the dried photoanode. A platinum (Pt) counter electrode was then placed over the electrolyte. Chenodeoxycholic acid was also added to the chlorophyll and their interactions were studied through absorption spectroscopy. The chlorophyll sensitized solar cells fabricated had the configuration glass $/ \mathrm{FTO} / \mathrm{TiO}_{2} /$ sensitizer/electrolyte/Pt/FTO/glass as shown in Figure 2.

\subsection{Characterizations}

2.5.1. Electrochemical Impedance Spectroscopy. In order to determine the bulk impedance of the GPE, it was inserted into a coin cell and mounted in a conductivity mount. The diameter of the cell was $2 \mathrm{~cm}$. The electrodes and electrolyte were held under spring pressure. The conductivity of the electrolyte can be calculated from the equation below:

$$
\sigma=\frac{t}{R_{b} A} .
$$

Here, $A$ is the electrode-electrolyte contact area and $t$ is thickness of the film. $R_{b}$ is the bulk resistance of the material

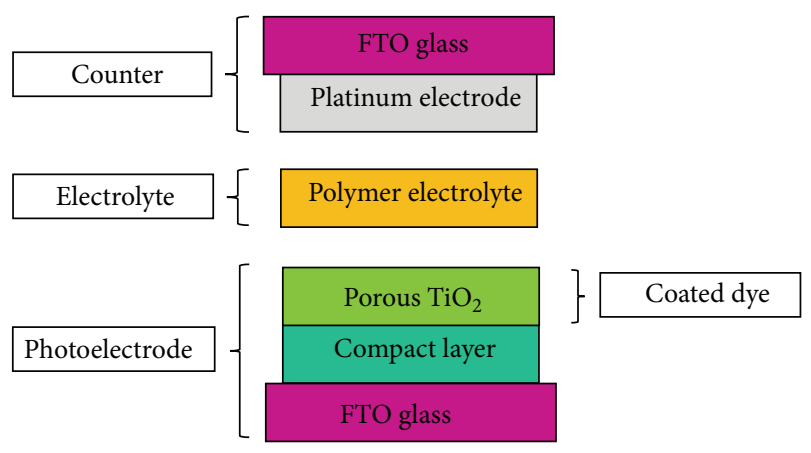

Figure 2: The DSSC assembly.

which can be obtained from the intersection of complex impedance plot with the real impedance axis.

2.5.2. UV-Vis Spectroscopy. The UV-Vis spectra of the chlorophyll-ethanol solution and the chlorophyll-ethanol solution added with chenodeoxycholic acid were taken using the UV3101PC Shimadzu UV-Vis-NIR scanning spectrophotometer. The chlorophyll-ethanol solution was scanned from $200 \mathrm{~nm}$ to $900 \mathrm{~nm}$. The chlorophyll-ethanol solution added with chenodeoxycholic acids was also taken in the same range.

2.5.3. J-V Measurements. The photocurrent density-photovoltage $(J-V)$ characteristics of the DSSCs under $100 \mathrm{~mW} \mathrm{~cm} \mathrm{~cm}^{-2}$ illumination were studied with a Keithley 2400 electrometer. The short circuit current density $\left(J_{\text {sc }}\right)$, open circuit voltage $\left(V_{\text {oc }}\right)$, fill factor $(\mathrm{FF})$, and energy conversion efficiency $(\eta)$ were calculated from the following equations:

$$
\mathrm{FF}=\frac{J_{\mathrm{opt}} V_{\mathrm{opt}}}{J_{\mathrm{sc}} V_{\mathrm{oc}}} .
$$

Here, $J_{\text {opt }}$ is optimum current density and $V_{\text {opt }}$ is optimum voltage. Consider

$$
\eta(\%)=\frac{J_{\mathrm{sc}} V_{\mathrm{oc}} \mathrm{FF}}{P_{\text {in }}} \times 100 \% .
$$

Here, $P_{\text {in }}$ is the total incident power density.

\section{Results and Discussion}

3.1. Electrochemical Impedance Spectroscopy. GPEs using LiI and LiI with TPAI salts and ethylene carbonate (EC) and propylene carbonate (PC) as the solvent have been prepared. The use of EC and PC ensures nonvolatility of the electrolyte [24]. EC has high dielectric constant (84), which is favorable for the dissociation of salts. However, EC has crystallization tendency at low temperatures. This can lead to phase separation between EC and the polymer matrix and may impede ion conduction when the GPE is subjected to an electric field. Hence, another organic solvent must be added. PC has been chosen as the second solvent because the use of a binary EC/PC solvent has resulted in high ionic conductivity [25]. Dimethyl sulfoxide (DMSO) was also used as solvent to ensure complete dissolution of the salts and polymer. 


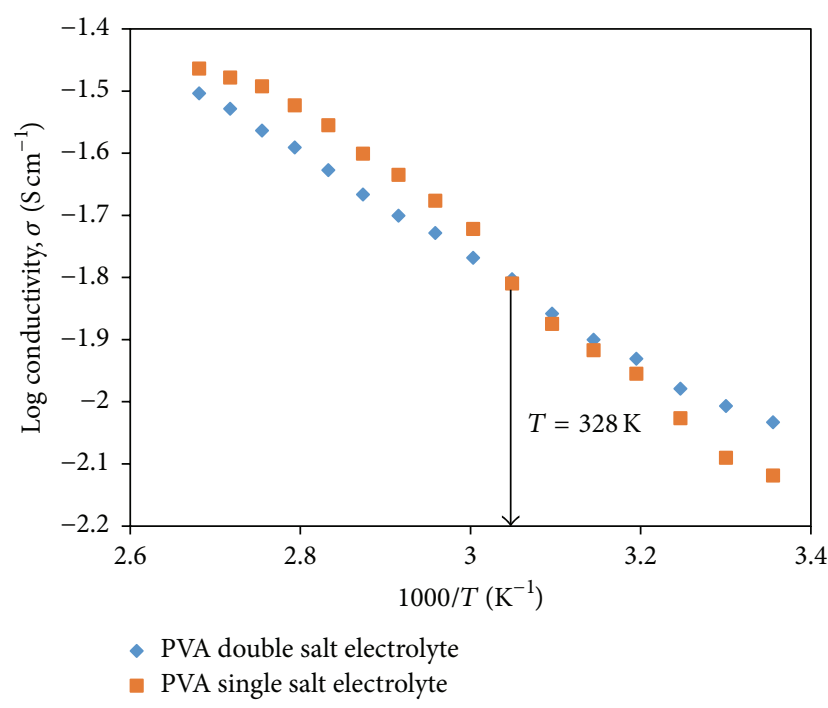

FIGURE 3: The log conductivity for PVA single and double salt varied temperature (298 K-373 K).

The graphs of conductivity with temperature for the single and double salt electrolytes were plotted and shown in Figure 3 from room temperature until $373 \mathrm{~K}$. It can be observed that, from $298 \mathrm{~K}$ until $328 \mathrm{~K}$, the conductivity of PVA double salt electrolyte is higher than the PVA single salt electrolyte but when the temperature increased above $328 \mathrm{~K}$, the conductivity of PVA single salt electrolyte is higher than the conductivity of the PVA double salt electrolyte.

Above $328 \mathrm{~K}$, conductivity of the PVA single salt electrolyte is higher than that of the double salt electrolyte. This could be attributed to the immobilization of some $\mathrm{TPA}^{+}$ cations in the double salt electrolyte due to the interaction between $\mathrm{TPA}^{+}$and oxygen in PVA. This reduces the number density of charge carriers in the double salt electrolyte. Another probable reason is the higher ion mobility of $\mathrm{K}^{+}$ion in the single salt electrolyte compared to the lower mobility of the TPA ${ }^{+}$cations and the reduced number density of $\mathrm{K}^{+}$ ions in the double salt electrolyte.

3.2. Absorption Spectroscopy. Figure 4 shows the absorption spectrum of chlorophyll solution in ethanol. The spectrum shown is in the visible wavelength range from $400 \mathrm{~nm}$ to $700 \mathrm{~nm}$. The chlorophyll in ethanol solution shows three distinct peaks at 436, 470, and $664 \mathrm{~nm}$. From the spectrum, we can also see that the absorption from $500 \mathrm{~nm}$ to $650 \mathrm{~nm}$ is low. The absorption in this region of the spectrum could also be contributed by ethanol solvent since ethanol shows a peak between $550 \mathrm{~nm}$ and $600 \mathrm{~nm}$ [26]. The spectrum is attributed to chlorophyll $a$.

The absorption results in Figure 4 are in reasonable agreement with that of Amao and Komori [27]. This dye will be then applied to the DSSC for the $J-V$ measurement to see its performance. It can be seen that there are three maxima in the absorbance spectrum of chlorophyll. The absorptions are observed to peak at 436 and $470 \mathrm{~nm}$ representing $\pi \rightarrow \pi^{*}$ transition and $664 \mathrm{~nm}$ absorbance peak represents the $\mathrm{n} \rightarrow$

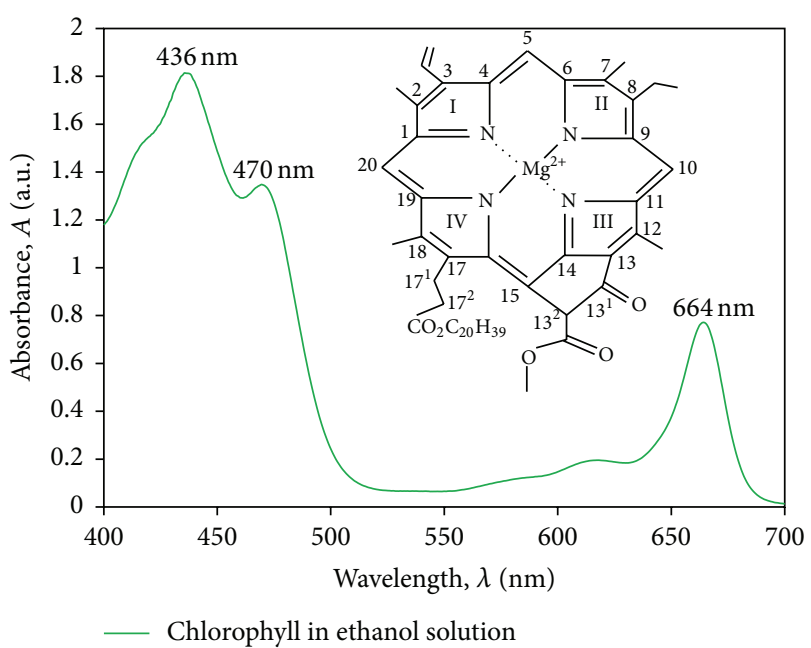

FIGURE 4: The absorption spectra of chlorophyll in ethanol solution.

TABLE 2

Mass of $\mathrm{TiO}_{2}$ electrode before soaking in chlorophyll solution

$1.5245 \mathrm{~g}$

Mass of $\mathrm{TiO}_{2}$ electrode after soaking in chlorophyll and drying

Mass of chlorophyll adhered

$1.5251 \mathrm{~g}$

$\pi^{*}$ transition. Compared to nonconjugated systems, transitions in chlorophyll require lesser energy for an electronic transition [28]. The amount of adsorbed dye on the $\mathrm{TiO}_{2}$ film was estimated as shown in Table 2.

Assuming the molecular weight of chlorophyll to be $893.5 \mathrm{~g} / \mathrm{mol}$, the amount of chlorophyll molecules adhered to the $\mathrm{TiO}_{2}$ electrode is $\sim 4 \times 10^{17}$ molecules. The next attempt is to add an organic acid as stabilizer to the chlorophyll solution. Chenodeoxycholic acid (CDCA) was used because it has a carboxylic group as in bis(isothiocyanato) bis $\left(2,2^{\prime}\right.$-bipyridyl$4,4^{\prime}$-dicarboxylato) ruthenium (II) or N3 dye by which it can be attached onto $\mathrm{TiO}_{2}$. Intramolecular charge transfer can then be promoted from the donor region of the dye to the region in the vicinity of the $\mathrm{TiO}_{2}$ substrate. A good number of reports on the structures and roles of carboxylic acid on optoelectronic performance of DSSC have been found elsewhere [13-18, 29]. CDCA has been extensively used for devices sensitized with dye [30] and to enhance the open circuit photovoltage, the short circuit photocurrent density, and the efficiency of DSSC [31].

CDCA is observed to stabilize the chlorophyll solution for a reasonably long period. According to Lee et al. [30] DSSCs exhibit good long-term stability when CDCA was used as coadsorbent in dye sensitizer. Figure 5 shows the absorption spectra of chlorophyll added with various amounts of CDCA. At $664 \mathrm{~nm}$ the spectrum for each sample has almost the same absorbance. On addition of $10 \mathrm{mM}$ CDCA the absorbance at 437 and $470 \mathrm{~nm}$ decreased. However addition of $5 \mathrm{mM}$ CDCA gives about the same absorbance as the CDCAfree chlorophyll solution. It can also be observed that the spectrum for $1 \mathrm{mM}$ of CDCA added to chlorophyll exhibits 


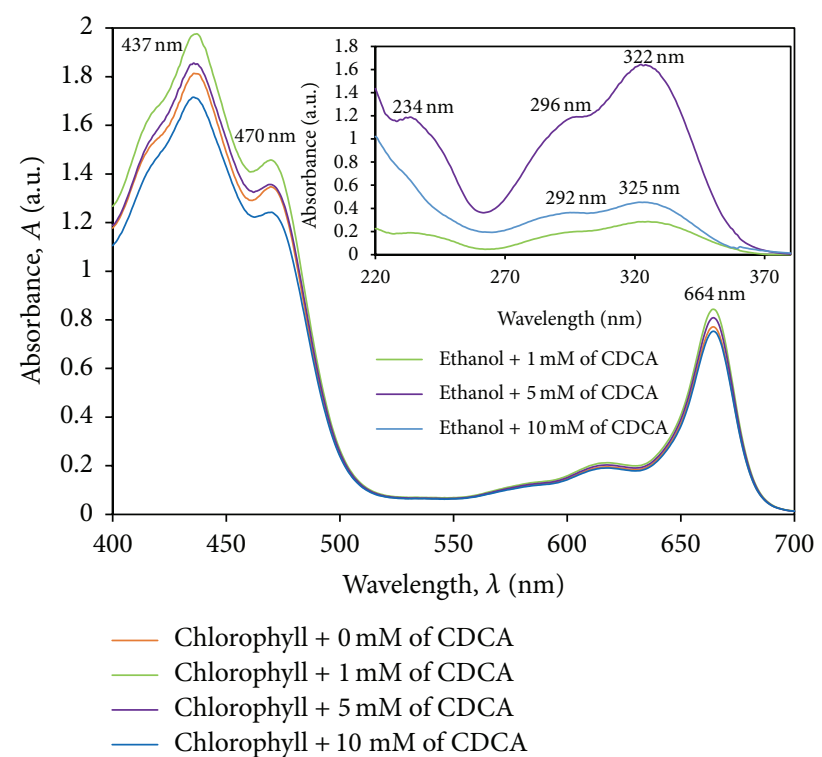

Figure 5: The absorption spectra of chlorophyll with various concentrations of CDCA.

TABLe 3: Photoelectrochemical parameters of DSSCs with PVA electrolytes containing single and double salts.

\begin{tabular}{lcccc}
\hline Electrolyte & $\begin{array}{c}J_{\mathrm{sc}} \\
\left(\mathrm{mA} \mathrm{cm}^{-2}\right)\end{array}$ & $\begin{array}{c}V_{\mathrm{oc}} \\
(\mathrm{V})\end{array}$ & FF & $\eta(\%)$ \\
\hline PVA + single salt & 4.59 & 0.61 & 0.64 & 1.77 \\
PVA + double salts & 5.96 & 0.58 & 0.58 & 2.00 \\
\hline
\end{tabular}

the highest absorbance at all significant peaks of chlorophyll. Therefore, it is expected that the DSSC fabricated by chlorophyll with $1 \mathrm{mM}$ CDCA would lead to the highest efficiency as more light is absorbed by the dye. However, on extending the absorbance curve into the UV region $(220 \mathrm{~nm}-370 \mathrm{~nm})$ (inset of Figure 5), highest absorbance peaks at $322 \mathrm{~nm}, 296 \mathrm{~nm}$, and $234 \mathrm{~nm}$ are found for $5 \mathrm{mM}$ CDCA + chlorophyll sample which may exhibit highest efficiency in corresponding DSSC.

It can be seen that the intensity of absorption spectrum of chlorophyll for various concentrations of CDCA is higher compared to that of the CDCA-free chlorophyll. Even with addition of $5 \mathrm{mM} \mathrm{CDCA}$, absorbance is still higher than that observed for chlorophyll without the additive. The absorption results show that the CDCA is a good stabilizing agent for chlorophyll dye [31].

3.3. J-V Measurement on DSSCs. The DSSCs sensitized with pure chlorophyll were illuminated with white light of intensity $1000 \mathrm{~W} / \mathrm{m}^{2}$ and the photocurrent-photovoltage $(J-V)$ curves were obtained. Figure 6 shows the $J-V$ characteristics of DSSCs with PVA based single and double salt electrolytes. The short circuit current density $\left(J_{s c}\right)$, open circuit voltage $\left(V_{\text {oc }}\right)$, fill factor $(\mathrm{FF})$, and efficiency $(\eta)$ obtained are listed in Table 3.

From Figure 6 and Table 3, it can be seen that the DSSC with PVA electrolyte containing double salts showed a higher efficiency of $2.00 \%$ compared to the DSSC with

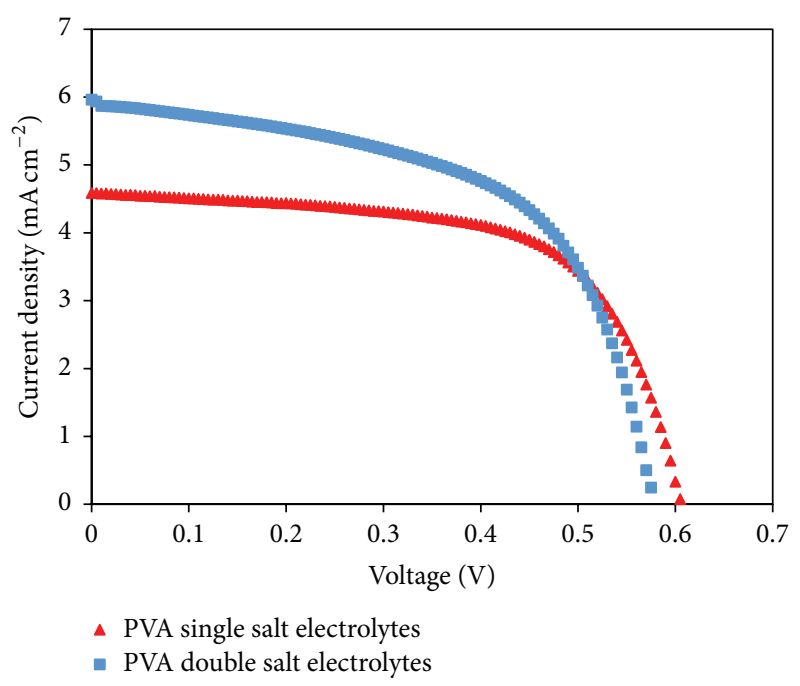

FIGURE 6: $J-V$ characteristics of DSSCs with PVA based electrolytes containing single and double salts.

PVA electrolyte containing single salt which exhibited an efficiency of only $1.77 \%$. It is to be noted that DSSC with gel polymer electrolytes and chlorophyll as the sensitizer usually exhibits efficiencies less than 1\% [32-38]. The short circuit current density for DSSC with PVA double salt electrolyte is $5.96 \mathrm{~mA} \mathrm{~cm}^{-2}$. This is higher than DSSC using PVA single salt electrolyte, $4.59 \mathrm{~mA} \mathrm{~cm}^{-2}$. This is due to the addition of TPAI salt to the electrolyte which may lower the Fermi level of $\mathrm{TiO}_{2}$. As a result, the rate of electron injection into the conduction band increased giving rise to a higher current density for the DSSC with PVA double salt electrolyte. This can also imply that the rate of electron recombination to the hole in the dye and to the triiodide ion in the electrolyte has been reduced. However, the open circuit voltage for DSSC with PVA double salt electrolyte is lower than the open circuit voltage of DSSC with PVA single salt electrolyte by $5 \%$. This result confirms that the Fermi level has been lowered towards the redox mediator potential. It can also be inferred from this result that the iodide ion conductivity is an important factor that contributes to $J_{\mathrm{sc}}$ of solar cells with $\mathrm{I}^{-} / \mathrm{I}_{3}{ }^{-}$mediator. In terms of number density of charge carriers PVA double salt electrolyte has higher $\mathrm{I}^{-}$ions compared to the PVA single salt electrolyte. This shows that PVA double salt electrolyte can produce faster $\mathrm{I}^{-}$to $\mathrm{I}_{3}{ }^{-}$and $\mathrm{I}_{3}{ }^{-}$to $\mathrm{I}^{-}$ion exchange leading to faster regeneration of the dye molecules. The number of $\mathrm{I}^{-}$in PVA single salt electrolyte as well as the rate of redox process is lower than that in PVA double salt electrolyte.

In an attempt to enhance the efficiency of the DSSC utilizing the double salt electrolyte, TBP was added to the electrolyte. It was thought that the efficiency may be improved further by increasing the $V_{\mathrm{oc}}$. By doing this we can also increase the fill factor, FF. With increase in FF, the amount of power delivered by the DSSC will be increased. According to Stergiopoulos et al. [39] the addition of TBP into PVA double salt electrolytes can increase $V_{\mathrm{oc}}$. It is known from literature that addition of TBP in an electrolyte can improve the efficiency of the DSSC [40]. Figure 7 shows the $J-V$ 


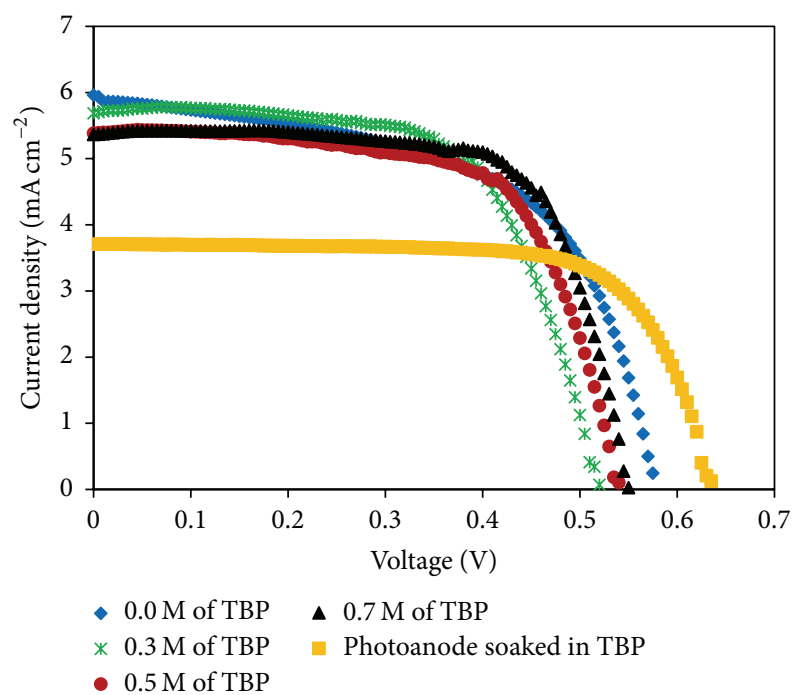

FIgURE 7: The $J-V$ characteristics for DSSCs with double salt PVA electrolyte containing various amounts of TBP and that of the DSSC with photoanode soaked in TBP for $1 \mathrm{~h}$.

TABLE 4: Performance parameters of DSSCs with double salt PVA electrolyte containing various amounts of TBP and that of the DSSC with photoanode soaked in TBP for $1 \mathrm{~h}$.

\begin{tabular}{lcccc}
\hline Sample & $\begin{array}{c}J_{\text {sc }} \\
\left(\mathrm{mA} \mathrm{cm}^{-2}\right)\end{array}$ & $\begin{array}{c}V_{\text {oc }} \\
(\mathrm{V})\end{array}$ & FF & $\eta(\%)$ \\
\hline $0.0 \mathrm{M}$ of TBP & 5.96 & 0.58 & 0.58 & 2.00 \\
$0.3 \mathrm{M}$ of TBP & 5.70 & 0.52 & 0.69 & 2.05 \\
$0.5 \mathrm{M}$ of TBP & 5.39 & 0.54 & 0.69 & 2.00 \\
$0.7 \mathrm{M}$ of TBP & 5.37 & 0.55 & 0.73 & 2.17 \\
Photoanode soaked in TBP & 3.71 & 0.64 & 0.72 & 1.69 \\
\hline
\end{tabular}

characteristics of the chlorophyll-ethanol based DSSCs with double salt electrolyte added with $0.3 \mathrm{M}, 0.5 \mathrm{M}$, and $0.7 \mathrm{M}$ $\mathrm{TBP}$ and the corresponding performance parameters which are also depicted in Table 4.

From Table 4, addition of $0.7 \mathrm{M}$ TBP in the electrolyte increased the efficiency of DSSC by $8.5 \%$ compared to the DSSC without TBP added.

The $J-V$ characteristics in Figure 7 showed that the DSSCs with double salt PVA electrolyte added with TBP exhibit a slight decrease of $V_{\text {oc }}$ compared to the DSSC with TBPfree electrolyte. From the results, it can be inferred that the Fermi level of the $\mathrm{TiO}_{2}$ has been lowered towards the redox potential therefore leading to lower $V_{\mathrm{oc}}$. It can also be observed that increasing the molarity of TBP to $0.5 \mathrm{M}$ resulted in $V_{\text {oc }}$ increase. This implied that the $\mathrm{TiO}_{2}$ Fermi level has been moved towards the conduction band edge of the semiconducting metal oxide and increased the difference between the Fermi and redox levels resulting in higher $V_{\mathrm{oc}}$, at the expense of $J_{\mathrm{sc}}$ that decreased with increase in TBP concentration. The decrease in $J_{\text {sc }}$ also implied that less photons are being absorbed because the chlorophyll harvest has decreased. Therefore, less electrons are excited and injected into the conduction band of the metal oxide
TABLE 5: Performance parameters of DSSCs with PVA based double salt electrolyte and chlorophyll added with various concentrations of CDCA.

\begin{tabular}{lcccc}
\hline Sample & $\begin{array}{c}J_{\mathrm{sc}} \\
\left(\mathrm{mA} \mathrm{cm}^{-2}\right)\end{array}$ & $\begin{array}{c}V_{\mathrm{oc}} \\
(\mathrm{V})\end{array}$ & FF & $\eta(\%)$ \\
\hline Chlorophyll + 0 mM of CDCA & 6.47 & 0.60 & 0.63 & 2.43 \\
Chlorophyll + 1 mM of CDCA & 7.69 & 0.52 & 0.62 & 2.46 \\
Chlorophyll + 5 mM of CDCA & 8.44 & 0.54 & 0.58 & 2.62 \\
Chlorophyll + 10 mM of CDCA & 9.00 & 0.50 & 0.58 & 2.60 \\
\hline
\end{tabular}

$\left(\mathrm{TiO}_{2}\right)$ semiconductor. Although $V_{\mathrm{oc}}$ of the DSSC with TBP added electrolyte is lower than $V_{\text {oc }}$ in the DSSC with TBP-free electrolyte, $V_{\text {oc }}$ increases with TBP concentration, though slightly, in DSSCs containing TBP. As can be seen the DSSC with TBP-free electrolyte gives $5.96 \mathrm{~mA} \mathrm{~cm}^{-2}$ of current density, $0.58 \mathrm{~V}$ of open circuit voltage, 0.58 of fill factor, and $2.00 \%$ of efficiency but when the electrolyte was added with $0.7 \mathrm{M}$ of TBP, the highest efficiency of $2.17 \%$ with $5.37 \mathrm{~mA} \mathrm{~cm}^{-2}$ of current density, $0.55 \mathrm{~V}$ of voltage, and 0.73 of fill factor was obtained.

In this work, the photoanode was also soaked in TBP. For the DSSC prepared by soaking the photoanode in TBP, $V_{\text {oc }}$ increased and $J_{\text {sc }}$ decreased. This showed that the surface states of $\mathrm{TiO}_{2}$, which governed the position of the Fermi level, were more affected by soaking the photoanode with TBP compared to the addition of TBP to the electrolyte. The efficiency of the DSSC with the photoanode soaked in TBP is low because of the reduced $J_{s c}$, which may be attributed to the reflection and scattering of light by TBP resulting in less photon harvest by the chlorophyll. The adsorption on the $\mathrm{TiO}_{2}$ surface by the pyridine ring induces electrons into the $\mathrm{TiO}_{2}$ creating a surface dipole. The band edge movement reduces the driving force for electron injection and thus $J_{\mathrm{sc}}$ is a little bit lower than in untreated cells [41]. By adding TBP to the electrolyte, this work has shown that, adding 0.7 M TBP into the electrolyte, the efficiency can be enhanced by $8.5 \%$ from $2.00 \%$ to $2.17 \%$.

So far the strategy in enhancing the efficiency of the DSSC is by using two salts and adding TBP to the electrolyte that acted to increase the open circuit voltage and increasing the ratio of maximum obtainable power to the product of the open circuit voltage and short circuit current. It is to be remembered that chlorophyll obtained is a natural pigment that is usually unstable but has strong adhesion to rocky surface.

Figure 8 shows the $J-V$ characteristics of DSSCs with double salt electrolyte and chlorophyll sensitizer added with different amounts of CDCA. No TBP was added to the electrolyte as the aim is to observe the effect of CDCA addition to the sensitizer. Table 5 lists the performance parameters of the DSSCs.

The $J-V$ characteristics for chlorophyll sensitizer added with CDCA showed best performance when $5 \mathrm{mM}$ of CDCA was added to chlorophyll. This cell has $J_{\mathrm{sc}}=8.44 \mathrm{~mA} \mathrm{~cm}^{-2}$, $V_{\mathrm{oc}}=0.54 \mathrm{~V}, \mathrm{FF}=0.58$, and efficiency of $2.62 \%$. From Table 5 it can be seen that $J_{\text {sc }}$ increases with the increase in CDCA concentration. The dye molecules adsorbed on the porous 


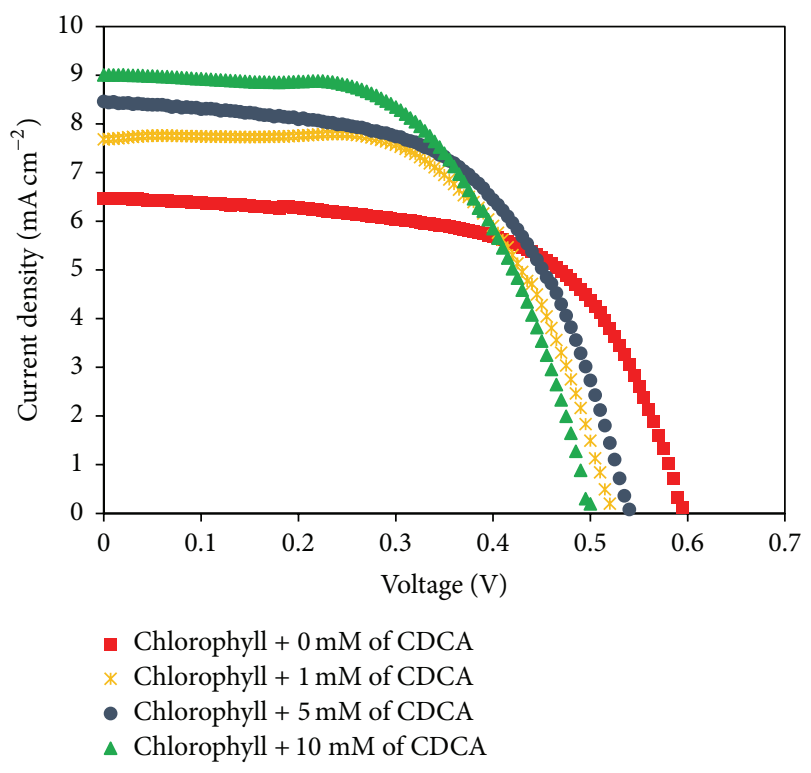

FIGURE 8: The $J-V$ characteristics of DSSCs with PVA based double salt electrolytes and chlorophyll added with various concentrations of CDCA.

$\mathrm{TiO}_{2}$ film decreased as the CDCA concentration in the dye sensitizer increased. This can be attributed to the competition between chlorophyll and CDCA molecules to assemble on the restricted $\mathrm{TiO}_{2}$ surface although an improvement in cell performance was observed using CDCA [30]. As mentioned CDCA has large hydrophobic tail and a hydrophilic head (-COOH group) for adsorption to the $\mathrm{TiO}_{2}$ surface and can reduce dye aggregation and electron recombination through the formation of a thin resistive layer on the vacant $\mathrm{TiO}_{2}$ surface [19-22]. Furthermore, CDCA reduces the intermolecular attraction between chlorophyll molecules resulting in dye stabilization. Li et al. [19] and Wooh et al. [20] also pointed out that adsorption of CDCA reduces the surface tension of $\mathrm{TiO}_{2}$ surface causing efficient suppression of electron recombination by hindering charged species coming from the electrolyte towards bare $\mathrm{TiO}_{2}$ sites. According to Sun et al. [42] and Garcia-Martin et al. [43] the peripheral Hbonding through carbonyl groups of chlorophyll $\left(\mathrm{C}-13^{1}, \mathrm{C}-\right.$ $13^{2}$, and $\mathrm{C}-17^{3}$ ) can regulate spin density of chlorophyll and electron density may be redistributed around porphyrin ring; that is, porphyrin ring can be distorted from its planar shape. Subsequently, the chlorophyll molecule can be attached to $\mathrm{TiO}_{2}$ surface through $\mathrm{C}-13^{1}=\mathrm{O} \cdots \mathrm{TiO}_{2}$ coordination (Figures 9 and 10) making electron transfer route. Kay and Gräetzel [13] also pointed out the importance of free carboxyl groups for adsorption and photosensitization on $\mathrm{TiO}_{2}$. Similarly, CDCA molecules are adsorbed through $-\mathrm{COO}^{-} \ldots \mathrm{TiO}_{2}$ coordination in parallel with chlorophyll. The hydrophobic portion of CDCA may insulate electron recombination and isolate individual chlorophyll molecule preventing coagulation. Also, the CDCA molecule may create $\mathrm{H}$-bond with C$13^{2}$ and $\mathrm{C}-17^{3}$ sites which stabilize the porphyrin ring.

Therefore, the overall injection of the electron into the conduction band of $\mathrm{TiO}_{2}[44]$ is increased leading to higher

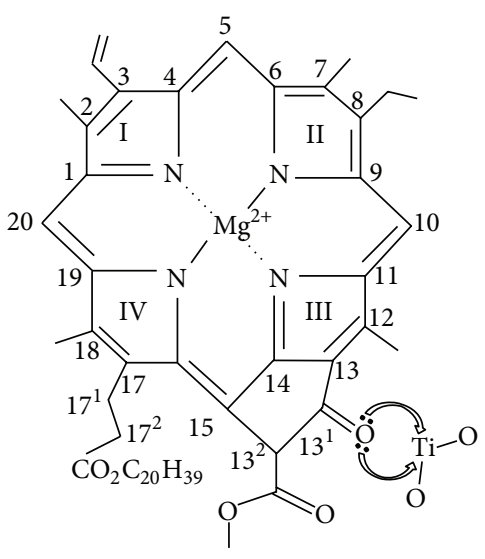

Chlorophyll- $\mathrm{TiO}_{2}$ interaction

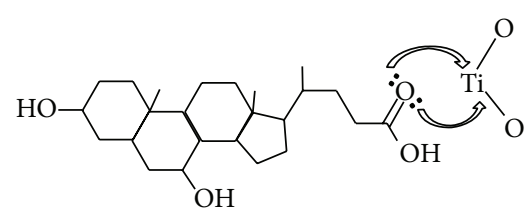

Chenodeoxycholic acid- (CDCA-) $\mathrm{TiO}_{2}$ interaction

Figure 9: Chlorophyll- $\mathrm{TiO}_{2}$ and $\mathrm{CDCA}-\mathrm{TiO}_{2}$ interaction on $\mathrm{TiO}_{2}$ surface.
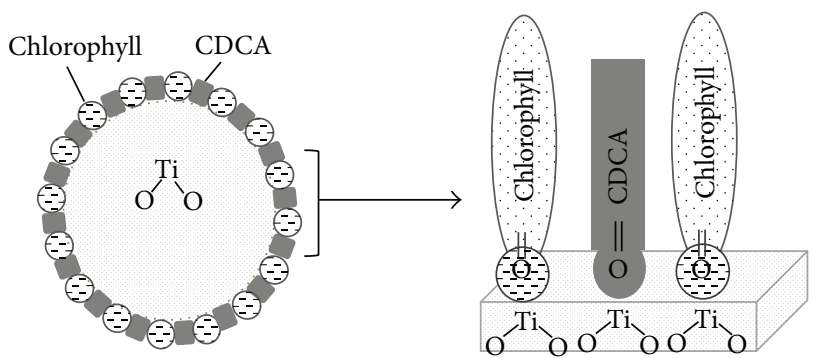

FIGURE 10: Schematic diagram of adsorption of Chlorophyll and CDCA molecule on $\mathrm{TiO}_{2}$ surface.

$J_{\text {sc }}$ with increasing CDCA concentration. $J_{\mathrm{sc}}$ of the DSSC is also governed by CDCA due to suppression of dark current at the semiconductor/electrolyte junction, since CDCA blocks the surface states $\mathrm{Ti}(\mathrm{IV})$ ions that are active in the charge transfer. Due to the insulating molecular layer, the charge recombination process can be shielded, and this increases the efficiency [45]. Consequently, CDCA also shifts the Fermi level of $\mathrm{TiO}_{2}$ to more negative potential which reduces the distance with the redox potential resulting in the decrease of $V_{\text {oc }}$ compared to the CDCA-free DSSC [46].

\section{Conclusions}

DSSCs with high photoelectric conversion efficiency have been prepared using chlorophyll dye extracted from Hyophila involuta. The absorption spectrum on chlorophyll sensitizer shows three peaks at 436,470 , and $664 \mathrm{~nm}$. This chlorophyll 
sensitizer produced a high power conversion efficiency of $2.00 \%$ when a PVA based double salt electrolyte was used. An addition of $0.7 \mathrm{M}$ TBP to the electrolyte has improved the efficiency up to $2.17 \%$. Addition of chenodeoxycholic acid (CDCA) can stabilize the chlorophyll and improve the efficiency of the chlorophyll based DSSCs. Much better performance was obtained with the addition of $5 \mathrm{mM} \mathrm{CDCA}$ to chlorophyll with efficiency reaching $2.62 \%$ due to better anchoring of the modified dye to the surface of $\mathrm{TiO}_{2}$.

\section{Conflict of Interests}

The authors declare that there is no conflict of interests regarding the publication of this paper.

\section{Acknowledgments}

The authors thank University of Malaya for the UMRG Programme RP003-13AFR for the funding in this project and Dr. Yong Kien Thai from Institute of Biological Sciences who confirmed the moss species.

\section{References}

[1] V. Shanmugam, S. Manoharan, S. Anandan, and R. Murugan, "Performance of dye-sensitized solar cells fabricated with extracts from fruits of ivy gourd and flowers of red frangipani as sensitizers," Spectrochimica Acta Part A: Molecular and Biomolecular Spectroscopy, vol. 104, pp. 35-40, 2013.

[2] W. Yanmin, "Recent research progress on polymer electrolytes for dye-sensitized solar cells," Solar Energy Materials and Solar Cells, vol. 93, no. 8, pp. 1167-1175, 2009.

[3] V. Somsongkul, C. Saekung, S. H. Thang, A. Wongchaisuwat, and M. Arunchaiya, "Composite poly(ethylene oxide) electrolyte modified with ethanol for dye-sensitized solar cells," Chiang Mai Journal of Science, vol. 38, no. 2, pp. 223-230, 2011.

[4] R. Kushwaha, P. Srivastava, and L. Bahadur, "Natural pigments from plants used as sensitizers for $\mathrm{TiO}_{2}$ based dye-sensitized solar cells," Journal of Energy, vol. 2013, Article ID 654953, 8 pages, 2013.

[5] J. Wu, Z. Lan, S. Hao et al., "Progress on the electrolytes for dyesensitized solar cells," Pure and Applied Chemistry, vol. 80, no. 11, pp. 2241-2258, 2008.

[6] A. K. Arof, M. Naeem, F. Hameed et al., "Quasi solid state dyesensitized solar cells based on polyvinyl alcohol (PVA) electrolytes containing $\mathrm{I}^{-} / \mathrm{I}_{3}^{-}$redox couple," Optical and Quantum Electronics, vol. 46, no. 1, pp. 143-154, 2014.

[7] K. P. Radha, S. Selvasekarapandian, S. Karthikeyan, M. Hema, and C. Sanjeeviraja, "Synthesis and impedance analysis of proton-conducting polymer electrolyte PVA: $\mathrm{NH}_{4} \mathrm{~F}$," Ionics, vol. 19, no. 10, pp. 1437-1447, 2013.

[8] K. Ryuzi, K. Motohiro, S. Kodate, A. Furube, N. Fuke, and N. Koide, "Effects of 4-tert-butylpyridine and li ions on photoinduced electron injection efficiency in black-dye-sensitized nanocrystalline $\mathrm{TiO}_{2}$ films," Journal of Physical Chemistry C, vol. 113, no. 48, pp. 20738-20744, 2009.

[9] X.-L. Wang, M. Wu, J. Ding, Z.-S. Li, and K.-N. Sun, "Periodic density functional theory study on the interaction mode and mechanism of typical additives with $\mathrm{TiO}_{2}$ substrates for dyesensitized solar cell applications," Journal of Power Sources, vol. 246, pp. 10-18, 2014.
[10] E. Alan, A Handbook of Malesian Mosses, Vol. 2: Leucobryaceae to Buxbaumiaceae, Natural History Museum Publications, London, UK, 1989.

[11] L. L. Tieszen and P. L. Johnson, "Pigment structure of some arctic tundra communities," Ecology, vol. 49, no. 2, pp. 370-373, 1968.

[12] H. Chang, M.-J. Kao, T.-L. Chen, C.-H. Chen, K.-C. Cho, and X.-R. Lai, "Characterization of natural dye extracted from wormwood and purple cabbage for dye-sensitized solar cells," International Journal of Photoenergy, vol. 2013, Article ID 159502, 8 pages, 2013.

[13] A. Kay and M. Gräetzel, "Artificial photosynthesis. 1. Photosensitization of titania solar cells with chlorophyll derivatives and related natural porphyrins," The Journal of Physical Chemistry, vol. 97, no. 23, pp. 6272-6277, 1993.

[14] P. Wang, S. M. Zakeeruddin, P. Comte, R. Charvet, R. Humphry-Baker, and M. Grätzel, "Enhance the performance of dye-sensitized solar cells by co-grafting amphiphilic sensitizer and hexadecylmalonic acid on $\mathrm{TiO}_{2}$ nanocrystals," Journal of Physical Chemistry B, vol. 107, no. 51, pp. 14336-14341, 2003.

[15] P. Wang, S. M. Zakeeruddin, R. Humphry-Baker, J. E. Moser, and M. Grätzel, "Molecular-scale interface engineering of $\mathrm{TiO}_{2}$ nanocrystals: improve the efficiency and stability of dyesensitized solar cells," Advanced Materials, vol. 15, no. 24, pp. 2101-2104, 2003.

[16] P. Wang, S. M. Zakeeruddin, R. Humphry-Baker, and M. Grätzel, "A binary ionic liquid electrolyte to achieve $\geq 7 \%$ power conversion efficiencies in dye-sensitized solar cells," Chemistry of Materials, vol. 16, no. 14, pp. 2694-2696, 2004.

[17] Z.-S. Wang, Y. Cui, Y. Dan-oh, C. Kasada, A. Shinpo, and K. Hara, "Thiophene-functionalized coumarin dye for efficient dye-sensitized solar cells: electron lifetime improved by coadsorption of deoxycholic acid," Journal of Physical Chemistry C, vol. 111, no. 19, pp. 7224-7230, 2007.

[18] S. Qu, W. Wu, J. Hua, C. Kong, Y. Long, and H. Tian, "New diketopyrrolopyrrole (DPP) dyes for efficient dye-sensitized solar cells," Journal of Physical Chemistry C, vol. 114, no. 2, pp. 1343-1349, 2010

[19] J. Li, W. J. Wu, J. B. Yang, J. Tang, Y. T. Long, and J. L. Hua, "Effect of chenodeoxycholic acid (CDCA) additive on phenothiazine dyes sensitized photovoltaic performance," Science China Chemistry, vol. 54, no. 4, pp. 699-706, 2011.

[20] S. Wooh, T.-Y. Kim, D. Song et al., "Surface modification of $\mathrm{TiO}_{2}$ photoanodes with fluorinated self-assembled monolayers for highly efficient dye-sensitized solar cells," ACS Applied Materials \& Interfaces, vol. 7, no. 46, pp. 25741-25747, 2015.

[21] Y.-S. Yen, T.-Y. Lin, C.-Y. Hsu et al., "A remarkable enhancement of efficiency by co-adsorption with CDCA on the bithiazolebased dye-sensitized solar cells," Organic Electronics: Physics, Materials, Applications, vol. 14, no. 10, pp. 2546-2554, 2013.

[22] J. H. Yum, S. J. Moon, R. Humphry-Baker et al., "Effect of coadsorbent on the photovoltaic performance of squaraine sensitized nanocrystalline solar cells," Nanotechnology, vol. 19, no. 42, Article ID 424005, 2008.

[23] M. F. Aziz, M. H. Buraidah, and A. K. Arof, "Dye-sensitized solar cells using binary iodide-PVA gel electrolyte," in Proceedings of the International Conference on Transparent Optical Networks, Cartagena, Spain, June 2013.

[24] O. A. Ileperuma, G. R. A. Kumara, H.-S. Yang, and K. Murakami, "Quasi-solid electrolyte based on polyacrylonitrile for dyesensitized solar cells," Journal of Photochemistry and Photobiology A: Chemistry, vol. 217, no. 2-3, pp. 308-312, 2011. 
[25] A. Subramania, E. Vijayakumar, N. Sivasankar, A. R. Sathiya Priya, and K.-J. Kim, "Effect of different compositions of ethylene carbonate and propylene carbonate containing iodide/ triiodide redox electrolyte on the photovoltaic performance of DSSC," Ionics, vol. 19, no. 11, pp. 1649-1653, 2013.

[26] B. C. Mphande and A. Pogrebnoi, "Impact of extraction methods upon light absorbance of natural organic dyes for dye sensitized solar cells application," Journal of Energy and Natural Resources, vol. 3, no. 3, pp. 38-45, 2014.

[27] Y. Amao and T. Komori, "Bio-photovoltaic conversion device using chlorine-e6 derived from chlorophyll from Spirulina adsorbed on a nanocrystalline $\mathrm{TiO}_{2}$ film electrode," Biosensors \& Bioelectronics, vol. 19, no. 8, pp. 843-847, 2004.

[28] P. Y. Bruice, Organic Chemistry, Pearson Education, Upper Saddle River, NJ, USA, 2004.

[29] A. Hagfeldt, G. Boschloo, L. Sun, L. Kloo, and H. Pettersson, "Dye-sensitized solar cells," Chemical Reviews, vol. 110, no. 11, pp. 6595-6663, 2010.

[30] K.-M. Lee, C.-Y. Chen, S.-J. Wu, S.-C. Chen, and C.-G. Wu, "Surface passivation: the effects of CDCA co-adsorbent and dye bath solvent on the durability of dye-sensitized solar cells," Solar Energy Materials and Solar Cells, vol. 108, pp. 70-77, 2013.

[31] C.-L. Lee, W.-H. Lee, and C.-H. Yang, "High efficiency of dyesensitized solar cells based on ruthenium and metal-free dyes," International Journal of Photoenergy, vol. 2013, Article ID 250397, 6 pages, 2013.

[32] G. R. A. Kumara, S. Kaneko, M. Okuya, B. Onwona-Agyeman, A. Konno, and K. Tennakone, "Shiso leaf pigments for dyesensitized solid-state solar cell," Solar Energy Materials and Solar Cells, vol. 90, no. 9, pp. 1220-1226, 2006.

[33] B.-Q. Liu, X.-P. Zhao, and W. Luo, "The synergistic effect of two photosynthetic pigments in dye-sensitized mesoporous $\mathrm{TiO}_{2}$ solar cells," Dyes and Pigments, vol. 76, no. 2, pp. 327-331, 2008.

[34] H. Chang, H. M. Wu, T. L. Chen, K. D. Huang, C. S. Jwo, and Y. J. Lo, "Dye-sensitized solar cell using natural dyes extracted from spinach and ipomoea," Journal of Alloys and Compounds, vol. 495, no. 2, pp. 606-610, 2010.

[35] H. Zhou, L. Wu, Y. Gao, and T. Ma, "Dye-sensitized solar cells using 20 natural dyes as sensitizers," Journal of Photochemistry and Photobiology A: Chemistry, vol. 219, no. 2-3, pp. 188-194, 2011.

[36] K. I. Kimpa, M. Momoh, K. U. Isah, H. N. Yahya, and M. M. Ndamitso, "Photoelectric characterization of dye sensitized solar cells using natural dye from Pawpaw Leaf and Flame Tree Flower as Sensitizers," Materials Sciences and Applications, vol. 3, no. 5, pp. 281-286, 2012.

[37] S. A. Taya, T. M. El-Agez, H. S. El-Ghamri, and M. S. Abdel-latif, "Dye-sensitized solar cells using fresh and dried natural dyes," International Journal of Materials Sciences and Applications, vol. 2, pp. 37-42, 2013.

[38] N. A. Ludin, A. M. A.-A. Mahmoud, A. B. Mohamad, A. A. H. Kadhum, K. Sopian, and N. S. Abdul Karim, "Review on the development of natural dye photosensitizer for dye-sensitized solar cells," Renewable and Sustainable Energy Reviews, vol. 31, pp. 386-396, 2014.

[39] T. Stergiopoulos, E. Rozi, C.-S. Karagianni, and P. Falaras, "Influence of electrolyte co-additives on the performance of dye-sensitized solar cells," Nanoscale Research Letters, vol. 6, article 307, 2011.

[40] B. Lee, D. B. Buchholz, P. Guo, D.-K. Hwang, and R. P. H. Chang, "Optimizing the performance of a plastic dye-sensitized solar cell," The Journal of Physical Chemistry C, vol. 115, no. 19, pp. 9787-9796, 2011.

[41] L. Yafeng, Z. Xiangzhen, Z. Huixing, G. Binbin, P. Aiying, and W. Mingdeng, "Improving the efficiency of dye-sensitized $\mathrm{Zn}_{2} \mathrm{SnO}_{4}$ solar cells: the role of $\mathrm{Al}^{3+}$ ions," Electrochimica Acta, vol. 56, pp. 9257-9261, 2011.

[42] Y. Sun, H. Wang, F. Zhao, and J. Sun, "The effect of axial $\mathrm{Mg}^{2+}$ ligation and peripheral hydrogen bonding on chlorophyll $a$," Chemical Physics Letters, vol. 387, no. 1-3, pp. 12-16, 2004.

[43] A. Garcia-Martin, L. G. Kwa, B. Strohmann, B. Robert, A. R. Holzwarth, and P. Braun, "Structural role of (bacterio)chlorophyll ligated in the energetically unfavorable $\beta$-position," The Journal of Biological Chemistry, vol. 281, no. 15, pp. 10626-10634, 2006.

[44] K. D. Seo, M. J. Lee, H. M. Song, H. S. Kang, and H. K. Kim, "Novel D- $\pi$-A system based on zinc porphyrin dyes for dyesensitized solar cells: synthesis, electrochemical, and photovoltaic properties," Dyes and Pigments, vol. 94, no. 1, pp. 143149, 2012.

[45] S. Ito, H. Miura, S. Uchida et al., "High-conversion-efficiency organic dye-sensitized solar cells with a novel indoline dye," Chemical Communications, no. 41, pp. 5194-5196, 2008.

[46] N. R. Neale, N. Kopidakis, J. van de Lagemaat, M. Grätzel, and A. J. Frank, "Effect of a coadsorbent on the performance of dye-sensitized $\mathrm{TiO}_{2}$ solar cells: shielding versus band-edge movement," The Journal of Physical Chemistry B, vol. 109, no. 49, pp. 23183-23189, 2005. 

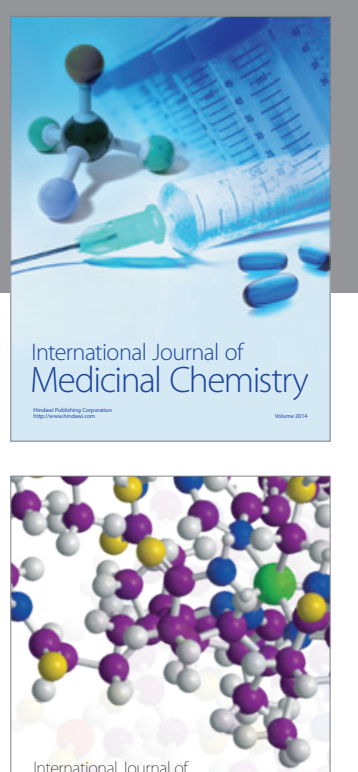

Carbohydrate Chemistry

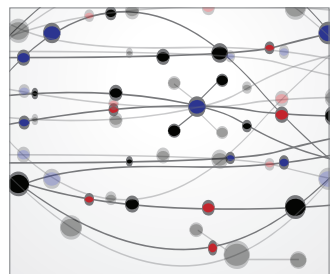

The Scientific World Journal
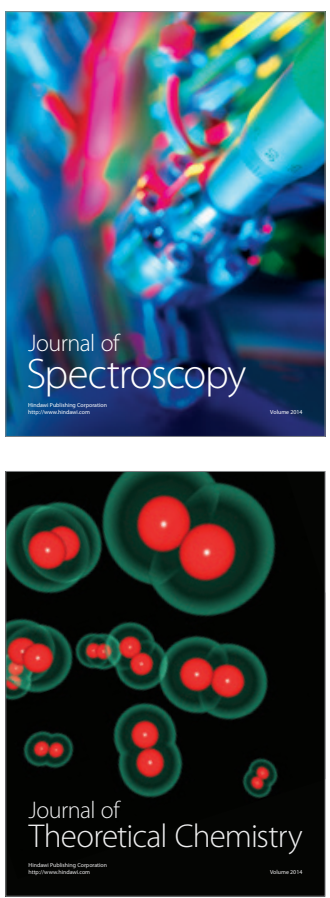
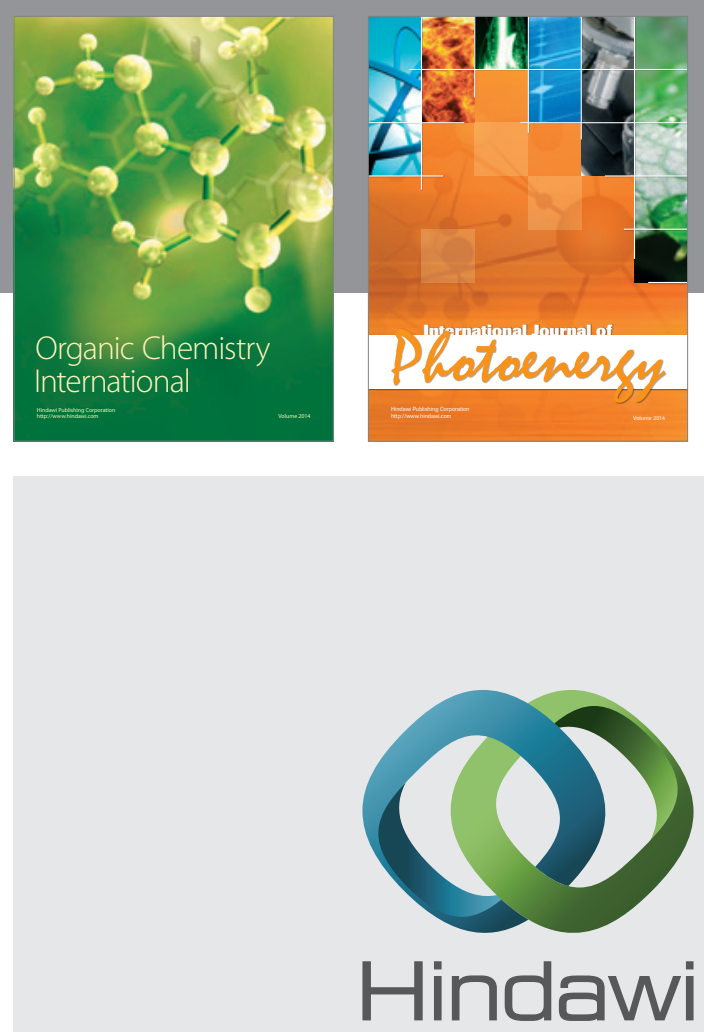

Submit your manuscripts at

http://www.hindawi.com

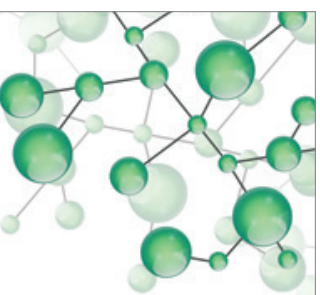

International Journal of

Inorganic Chemistry

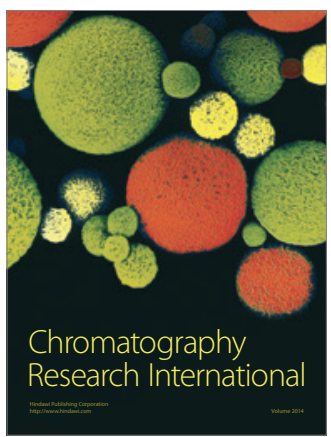

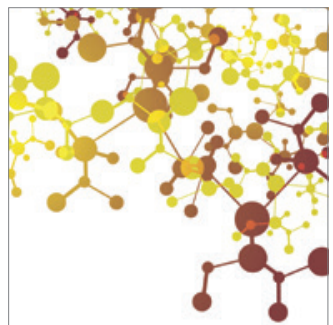

Applied Chemistry
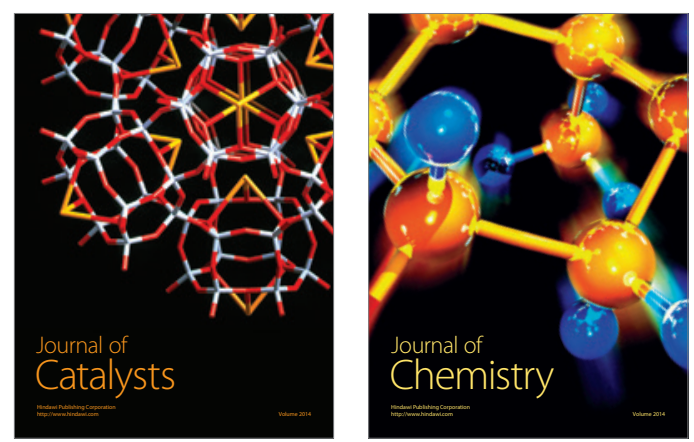
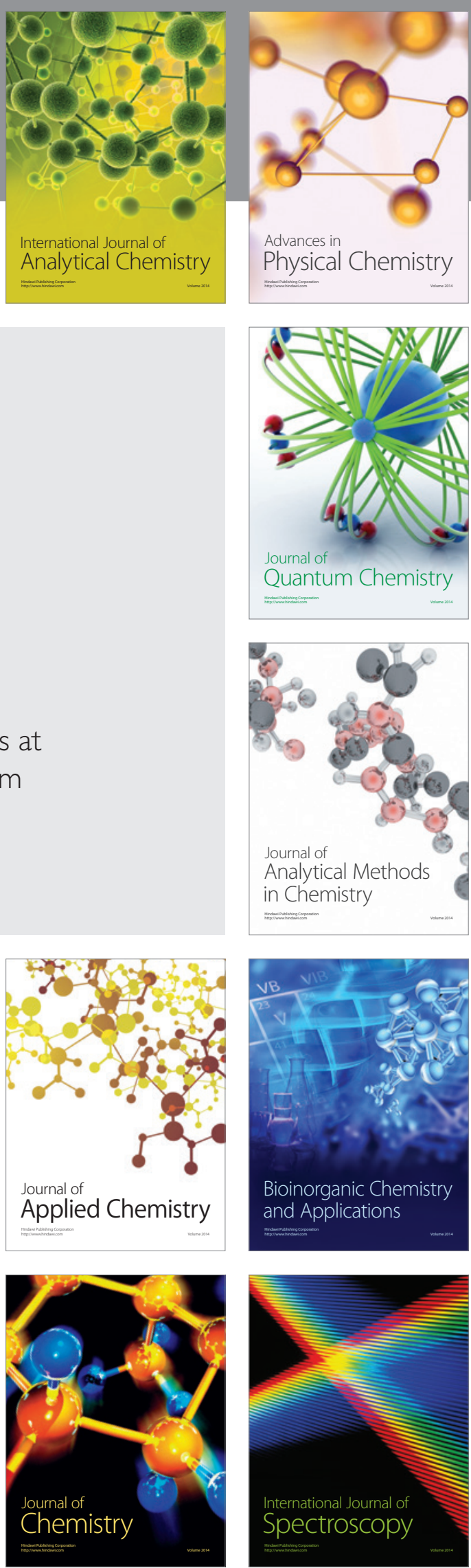